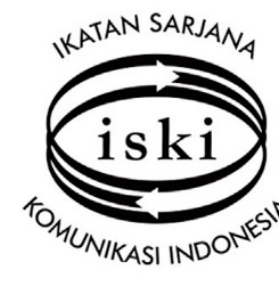

\title{
Resepsi Khalayak Wanita atas Karakter Ji Sun Woo dalam Drama Korea The World of the Married
}

\author{
https://doi.org/10.25008/wartaiski.v3i02.58 \\ Destaria Verani Soe'oed ${ }^{1 *}$, Prudensius Maring ${ }^{2}$ \\ ${ }^{1,2}$ Magister Ilmu Komunikasi, Universitas Budi Luhur \\ Jl. Ciledug Raya, Petukangan Utara, Jakarta 12260 - Indonesia \\ e-mail Korespondensi: desta.verani@gmail.com
}

Submitted: 04-07-2020, Revised: 26-11-2020, Accepted: 18-12-2020

Accredited by Kemristekdikti No. 30/E/KPT/2019

\begin{abstract}
Korean drama is a new phenomenon in the Indonesian society and has flooded audiences through various types of mass media. With an interesting story plot, Indonesian viewers have finally become active audiences and produced various meanings of the Korean drama content. The Korean drama, to be studied in this research, is The World of the Married. The drama aired on Trans TV station is considered successful in hypnotizing female audiences, and made the audiences adopt the story into their daily lives. This study aims to describe the female audiences' reception of Ji Sun Woo's leading character in this Korean drama titled The World of the Married, using Stuart Hall's reception theory and Hartsock's Standpoint Theory. The type of this research is qualitative. This research focuses on the audiences' decoding of perception, thinking, and interpretation. Data were obtained from in-depth interviews with female informants aged 25-30 years who had consistently watched this Korean drama from beginning to end. The results of this study indicate that in the interpretation of Ji Sun Woo's character, the age, gender, education, and experience of the Korean drama's viewers greatly influence the way of how informants give meaning to this character.
\end{abstract}

Keywords: Korean drama; mass media; reception theory; standpoint theory; the world of the married

\begin{abstract}
Abstrak
Drama korea merupakan fenomena baru yang kuat di masyarakat Indonesia. Drama korea membanjiri khalayak dari berbagai media massa. Dengan plot cerita yang menarik, penonton Indonesia akhirnya menjadi penonton aktif dan memproduksi berbagai arti dari sajian drama korea terebut. Drama korea yang diangkat dalam penelitian ini adalah The World of the Married. Drama tersebut ditayangkan di TransTV dianggap berhasil menghipnotis khalayak wanita, serta membuat para khalayak tersebut mengadopsi cerita tersebut kedalam kehidupan seharihari mereka. Penelitian ini bertujuan untuk mendeskripsikan resepsi penonton wanita dari karakter utama Ji Sun Woo dalam drama korea berjudul The World of the Married menggunakan teori penerimaan Stuart Hall, dan Standpoint Theory dari Hartsock. Jenis penelitian ini adalah kualitatif dan fokus pada decoding penonton dari persepsi, pemikiran, dan interpretasi. Data diperoleh dari wawancara mendalam dengan informan wanita usia 2530 tahun yang konsisten menyaksikan K-drama ini dari episode 1 sampai selesai. Hasil penelitian ini menunjukkan bahwa dalam pemaknaan karakter Ji Sun Woo, usia, jenis kelamin, pendidikan, dan pengalaman sangat mempengaruhi cara informan memberikan makna kepada karakter tersebut.
\end{abstract}

Kata Kunci: Drama Korea; media massa; teori resepsi; teori standpoint; the world of the married

\section{PENDAHULUAN}

Komunikasi dapat disampaikan dalam berbagai macam bentuk, lisan, tulisan, verbal, ataupun nonverbal. Menurut Laswell (dalam Elvinaro 2007: 29), komunikasi adalah pesan yang disampikan kepada komunikan (penerima) dari komunikator (sumber) melalui saluran-saluran tertentu, secara langsung maupun tidak langsung untuk memberikan efek kepada komunikan sesuai yang diinginkan 
komunikator, dan memenuhi unsur who, says what, in which channel, to whom, with what effect. Salah satu bentuk komunikasi menurut Elvinaro (2007: 3) adalah pesan yang disampaikan kepada banyak orang melalui media massa.

Menonton drama melalui media massa telah menjadi bagian dari kehidupan masyarakat, sebagai salah satu bentuk hiburan yang dapat memenuhi imajinasi khalayak serta berkaitan erat dengan berbagai aspek kehidupan sehari-hari (Ritonga, et.al 2019). Proses pembuatan drama mengandung banyak tujuan, salah satunya adalah pesan kunci yang ingin disampaikan.

Drama dan film menjadi alat kontruksi realitas yang melibatkan bahasa dalam konseptualisasi dan narasi (Siregar, et.all, 2019; Berto, 2018; Faizal, 2017, Purnamasari, 2020). Informasi yang tersaji dalam sebuah tayangan film atau drama dapat memberikan pengetahuan baru bagi masyarakat. Aspekaspek yang disajikan dalam sebuah drama seperti alur cerita, karakter tokoh atau pemain, kostum, ilustrasi musik, dan setting adalah hal-hal yang membuat khalayak tertarik untuk mengikuti setiap episode drama.

Cukup banyak penelitian yang dilakukan terkait tayangan drama di media massa. Penelitian terdahulu yang tergolong sejenis dengan studi ini pernah dilakukan oleh Bagas Putro dan Sri Budi Lestari dari Universitas Diponegoro tahun 2017 dengan judul Pemaknaan khalayak pada resistensi perempuan dalam film Sucker Punch. Temuan penelitian ini adalah adanya budaya patriarki yang kuat dan perempuan ditempatkan sebagai insan kelas nomor dua setelah laki-laki.

Berbeda dengan studi Putri dan Lestari, penelitian ini membahas tentang resepsi atau pemaknaan khalayak atas karakter utama pada tayangan drama Korea (biasa disebut K-Drama) dengan judul The World of the Married yang ditayangkan di Trans TV. Drama itu berhasil menembus rating tertinggi sepanjang sejarah tayangan drama Korea (Pangerang, 2020). Drama Korea belakangan ini menjadi perbincangan di Tanah Air (Ramadhani, 2020).

The World of the Married, diperankan oleh Kim Hee-Ae dan Park Hae-Joon, dianggap berhasil membuat penontonnya larut, terbawa emosi. Jalan ceritanya berkisah tentang perselingkuhan yang kerap memberikan plot twist tak terduga. Plot cerita tidak hanya mengenai kisah cinta dan konflik keluarga, namun juga membahas gender, karier dan permasalahan dalam sebuah kelompok sosial. Gender sendiri merupakan sebuah konstruksi sosial dan komodifikasi perbedaan antarseks. Konsep gender ini menjelaskan mengenai hubungan antara laki-laki dan perempuan. Selain itu dalam kajian feminisme, gender bermakna ciri atau sifat yang dihubungkan dengan jenis kelamin tertentu, baik berupa kebiasaan, budaya, maupun perilaku psikologis, bukan perbedaan secara biologis (Mansoer, 1996).

Serial K-Drama merupakan salah satu bentuk dari produksi budaya populer atau pop culture. Budaya populer erat kaitannya dengan isu-isu gender di dalamnya. Bentuk budaya populer biasanya terdapat isu gender, yaitu seperti dalam sebuah iklan, film, lagu, serial televisi, serta majalah. Isu gender tersebut dibuat secara sengaja untuk mengonstruksikan suatu hal, misal seperti mengonstruksi citra diri seorang perempuan maupun laki-laki. Maka dari itu, dalam serial K-drama The World of the Married terdapat penggambaran citra diri seorang perempuan dengan sosok sebagai Ji Sun Woo.

Rumusan masalah penelitian ini adalah, bagaimana pemaknaan khalayak wanita terhadap karakter Ji Sun Woo? Tujuan penelitianya adalah untuk mengetahui pemaknaan para khalayak wanita atas karakter wanita bernama Ji Sun Woo dalam drama The World of the Married yang dianggap memberi impresi kuat kepada para khalayak wanita. Teori yang digunakan adalah teori pemaknaan dengan fokus utama pada konsep decoding gagasan Stuart Hall serta Standpoint Theory dari Hartsock.

\section{KERANGKA TEORI}

K-Drama atau sering disapa drama Korea popular di Indonesia beberapa tahun belakangan ini melalui tayangan televisi. Biasanya drama Korea memiliki beberapa episode yang kian hari kian menarik. Drama-jenis ini pada awalnya muncul karena terjadi krisis keuangan di Asia pada tahun 1996 sehingga pemerintah Korea membuat anggaran khusus untuk membangkitkan industri hiburan di Korea. Pada saat itu drama Korea dikembangankan secara bertahap, mulai secara lokal, nasional hingga internasional, mencontoh telenovela dari Meksiko sedang berjaya saat itu di sejumlah negara Asia. Popularitas drama Korea terus meningkat hingga tahun 2000-an mampu menguasai pasar Asia atau sering disebut sebagai Korean Wave (Hendarwati, 2019).

Rating drama The World of the Married, sejak penayangan episode pertama, terus melonjak. Hingga episode 16, drama ini mencetak rekor baru sebagai drama dengan rating tertinggi yang pernah 
dicapai oleh drama di jaringan televisi kabel Korea. Menurut Mo Wan-il, Produser The World of the Married, hal yang membuat drama ini menarik dan berbeda adalah fokus drama tidak hanya pada si karakter utama Ji Sun Woo, tapi pada seluruh hubungan yang melibatkan karakter tersebut (Ji Won Choi, 2020).

Drama Korea The World of the Married mengakhiri keseluruhan jalan ceritanya pada Sabtu, 16 Mei 2020. Akhir The World of the Married ditutup dengan rating puncak yang sangat memuaskan, yaitu $28,3 \%$ untuk skala nasional dan 31,6\% untuk penonton di kawasan Seoul. Angka ini menjadikan drama yang diproduksi stasiun TV JTBC ini menjadi serial dengan rating paling tinggi dalam sejarah TV kabel Korea Selatan (Review Drakor, 2020).

Kim Hee Ae, pemeran dari Ji Sun Woo, mengungkapkan dalam sebuah wawancara, karakter Ji Sun Woo yang ia perankan dalam drama itu adalah sosok pribadi yang keras kepala namun selalu jujur terhadap tindakannya serta relate dengan banyak orang di luar sana (Karnita,2020). Keberhasilan drama Korea menjangkau khalayak luas tidak dapat dipisahkan dari penggunaan media massa.

Menurut McQuail (2011: 76), media massa memiliki ciri utama, yaitu dirancang untuk menjangkau banyak orang. Definisi komunikasi massa sebagai proses, bergantung pada ciri objektif produksi dan distribusi massa yang dimiliki oleh beberapa media berbeda. Media massa mempunyai peran penting dalam proses sosialisasi nilai-nilai tertentu dalam masyarakat. Salah satunya tampak pada fungsi transmisi yaitu mengirimkan warisan sosial dan edukasi pada khalayaknya.

Resepsi berasal dari bahasa latin yaitu recipere, dapat diartikan sebagai penyambutan atau penerimaan khalayak. Resepsi dengan pengertian secara luas yaitu, cara-cara pemberian makna dan pengolahan teks terhadap suatu tayangan, sehingga khalayak memberikan respon terhadapnya. Teori resepsi berfokus kepada bagaimana khalayak dalam menerima pesan, bukan pada pengirim pesan.

Pemaknaan pesan bergantung pada latar belakang budaya dan pengalaman hidup khalayak itu sendiri. Menurut John Downing, Ali Mohammad, dan Annabelle Sreberny dalam buku Questioning the Media: A Critical Introduction, khalayak melalui pengalaman dan latar belakang memiliki cara tersendiri dalam membaca dan memaknai teks media. Sebagaimana khalayak tersebut berasal dari latar belakang pendidikan, budaya dan psikografis yang berbeda maka mereka pun akan memiliki perbedaanperbedaan dalam memaknai teks atau pesan media (Mahardika,2014).

Dalam teori ini, Stuart Hall mengatakan, makna yang dimaksudkan dan yang diartikan dalam sebuah pesan bisa terdapat perbedaan. Kode yang digunakan atau disandi (encode) atau yang disandi balik (decode) tidak selamanya berbentuk simetris. Derajat simetri dalam teori ini dimaksudkan sebagai derajat pemahaman serta kesalahpahaman dalam pertukaran pesan dalam proses komunikasi, tergantung pada relasi ekuivalen (simetri atau tidak) yang terbentuk diantara encoder dan decoder.

Selain itu, encoder dan decoder, jika dipersonifikasikan menjadi pembuat pesan dan penerima pesan. Ketika khalayak menyandi balik atau decoding dalam suatu komunikasi, maka terdapat tiga posisi hipotekal, yaitu: pertama, Posisi Hegemoni Dominan (Dominant-hegemonic position). Posisi ini terjadi ketika tanpa sengaja khalayak memaknai pesan yang terkonotasi. Posisi ini disebut ideal dalam sebuah komunikasi transparan, dengan setiap individu bertindak terhadap sebuah kode sesuai apa yang dirasakan mendominasi untuk memiliki kekuatan lebih pada kode lainnya (Morissan, 2013).

Kedua adalah Negotiated Position. Posisi ini ialah ketika khalayak sudah mampu menerima ideologi yang dominan dan mereka akan bergerak untuk menindaklanjutinya dengan beberapa pengecualian.

Ketiga, posisi Oppositional Position. Posisi ini digambarkan ketika halayak menerima dan telah mengerti baik secara literal maupun konotasi konotasi yang diberikan. Namun halayak menyandinya dengan bertolak belakang. Ini hanya terjadi ketika khalayak memiliki sudut pandang kritis dalam menolak segala bentuk pesan yang disampaikan media dan memilih mengartikannya sendiri (Dinanti, 2010). Terkait dengan sudut pandang, Griffin menyatakan: "Sudut pandang adalah tempat untuk memandang dunia sekitar kita dengan kritis" (Griffin, 2009).

Teori Standpoint atau disebut juga sebagai teori sikap merupakan sebuah teori yang dapat mengubah kekuasaan seseorang melalui kewenangan suara pribadi individu. Teori Standpoint dipelopori oleh filsuf Jerman, George Wilhelm Friedrich Hegel tahun 1807. Teori ini membahas hubungan antara tuan dan budak. Walaupun tuan dan budak hidup dalam ruang lingkup yang sama, tetapi mereka memiliki pengetahuan dan pengalaman yang berbeda. Hal tersebut disebabkan posisi mereka berbeda dalam kehidupan sosial. Kemudian teori ini dikembangkan oleh Nancy Hartsock.

Hartsock mengembangkan teori ini dan memiliki pandangan tentang hubungan antara pria dan 
wanita. Hartsock mencampurkan teori standpoint tersebut dengan teori feminisme yang berpandangan bahwa wanita memiliki posisi sosial untuk mengakhiri penindasan. Nancy Hartsock menggunakan ideide dari Hegel dan Karl Marx untuk mengadaptasi Standpoint Theory dalam menguji hubungan antara wanita dan pria. Dengan ide inilah tahun 1983, Hartsock mempublikasikan The Feminist Standpoint: Developing the Ground for a Specially Feminist Historical Materialism. Hartsock tertarik dengan debat feminisme dan Marxisme yang berkembang pada tahun 1970 dan awal 1980. Debat ini terfokus pada ketiadaan isu-isu perempuan pada teori-teori Marxis.

Hartsock mengaplikasikan konsep yang dikemukakan oleh Hegel mengenai tuan dan budak dan juga gagasan Marx mengenai kelas dan kapitalisme terhadap isu seks dan gender. Orang kemudian lebih menggunakan istilah Standpoint Theory daripada Feminist Standpoint Theory. Ini dikarenakan tidak terdapat konsensus mengenai arti "feminis" itu sendiri. Banyak peneliti yang membuat definisi mengenai "feminis". Namun, Hartsock memiliki definisinya sendiri. Menurut Hartsock, feminisme fokus pada posisi sosial wanita dan keinginan untuk mengakhiri penindasan berdasarkan gender (West \& Turner, 2007).

Sebagaimana dikatakan oleh teori standpoint, perempuan harus dilihat sebagai konsumen aktif dalam realitasnya dan perspektif pribadi individu merupakan sumber informasi terpenting terhadap pengalaman mereka. Standpoint theory memberikan otoritas kepada perempuan untuk memiliki serta menyuarakan pengalaman dan pendapatnya sendiri. Standpoint perempuan tidak hanya sekadar cara pandang atau cara perempuan mengetahui sesuatu, tetapi lebih jauh sebagai sebuah pembuktian tentang keberadaan perempuan di dunia.

Teori standpoint memiliki tiga konsep penting, yakni standpoint, situated knowledge, serta sexual division of labor. Konsep kunci yang pertama, yaitu Standpoint dalam konteks dunia kerja, perempuan kerap dipengaruhi oleh standpoint dominan. Perempuan harus mampu membagi peran di sektor publik dan sektor domestik secara seimbang. Dunia ini dipisahkan lewat adanya pembagian peran dalam dunia kerja, yaitu laki-laki berurusan dengan dunia publik, sementara perempuan terlibat dalam dunia privat (Arivia, 2006). Konsep kedua, Situated Knowledge. Pada posisi ini, perempuan dan laki-laki selalu disosialisasikan kepada nilai-nilai ideal dalam hal menjadi perempuan dan laki-laki. Sosialisasi tersebut berlangsung dalam berbagai bentuk institusi, seperti keluarga, pendidikan, sosial, serta agama yang mampu mengarahkan manusia terhadap peran-peran yang seharusnya mereka lakukan. Perempuan sejak kecil telah diarahkan untuk menjadi ibu dan istri, sehingga ketika mereka bekerja pun, peran sebagai istri dan ibu tetap dilekatkan kepada perempuan karena mereka dianggap sebagai sosok yang sudah seharusnya menjalani peran tersebut.

Konsep ketiga, yaitu Sexual division of labor. Sebagai contoh, dalam dunia militer, pembagian kerja antara perempuan dan laki-laki berlangsung ketika pada awalnya prajurit perempuan hanya diposisikan pada bidang kerja yang bersifat administratif, perawatan kesehatan, dan pembinaan personil. Bidang pekerjaan tersebut dianggap cocok bagi perempuan karena mereka memiliki ketelitian, ketekunan, kesabaran, serta sifat-sifat keibuan. Hal ini dapat membatasi perempuan untuk lebih mengembangkan diri dan mencapai jenjang karir yang lebih baik. Konstruksi sosial seperti ini yang cenderung mereduksi peran perempuan dalam sektor kerja (Putriana, 2012)

Menurut West \& Turner, inti dari teori ini adalah untuk memberikan sebuah kerangka untuk memahami sistem kekuasaan. Kerangka tersebut dibangun berdasarkan pada pengetahuan yang diangkat dari kehidupan manusia sehari-hari, yaitu individu adalah konsumen aktif dalam realitasnya dan perspektif pribadi individu merupakan sumber informasi terpenting terhadap pengalaman mereka.

Standpoint theory memberikan otoritas kepada setiap orang untuk memiliki pendapatnya sendiri (Putriana, 2012). Kesimpulan dari teori sikap adalah bahwa semua orang atau individu dapat memiliki pendapat yang sama, tetapi mereka bisa memiliki sudut pandang yang berbeda. Perbedaan tersebut dapat terjadi karena adanya perbedaan pengalaman, pemikiran, pembelajaran, dan pengetahuan dalam lingkungan sosial yang berbeda pula.

\section{METODE PENELITIAN}

Metode adalah cara-cara yang teratur dan berpikir baik-baik untuk mencapai maksud, sedangkan metodologi adalah proses, prinsip, dan prosedur yang kita gunakan untuk mendekati problem dan mencari jawaban (Sobur, 2012).

Penelitian ini adalah penelitian kualitatif dengan metode analisis resepsi. Metode kualitatif digunakan untuk menganalisis berbagai masalah ilmu sosial humaniora, seperti demokrasi, ras, gender, 
kelas, negara bangsa, globalisasi, kebebasan, dan masalah-masalah kemasyarakatan pada umumnya (Ratna, 2010).

Penelitian ini menggunakan dua sumber data, yaitu data primer dan data sekunder. Data primer yang digunakan dalam penelitian ini adalah wawancara mendalam kepada informan terpilih. Wawancara dilakukan terhadap informan yang memiliki latar belakang berbeda karena ingin menggali pemaknaan karakter drama dari masing-masing individu tersebut. Sedangkan data sekunder diperoleh dari tinjauan pustaka buku-buku, penelitian terdahulu, sumber internet, dan sumber data lain untuk mendukung penelitian ini.

Teknik pengumpulan data yang dilakukan adalah wawancara mendalam dengan informan dengan tiga kualifikasi kunci, yaitu mereka haruslah seorang wanita, baik belum menikah ataupun sudah menikah; memiliki rentang usia dari 25 sampai 30 tahun, dan menonton drama The World of the Married secara lengkap mulai dari episode pertama hingga episode 16.

\section{HASIL PENELITIAN}

Proses decoding dari studi kultural Stuart Hall, ketika khalayak melakukan decoding maka melibatkan persepsi, pemikiran, dan interpretasi yang dimiliki oleh masing-masing individu. Dalam proses decoding, faktor-faktor seperti usia, jenis kelamin, pendidikan, dan juga pengalaman dalam komunitas mempengaruhi khalayak saat memaknai pesan.

Terkait dengan teori Sikap, teori ini memberikan titik masuk untuk memahami beberapa dinamika dalam memahami posisi relatif perempuan terhadap sistem kekuasaan. Kerangka ini dibangun pada pengetahuan yang dihasilkan dari kehidupan sehari-hari. Individu merupakan konsumen aktif dari realitas mereka sendiri dan bahwa perspektif individu merupakan informasi yang paling penting tentang pengalaman mereka.

Teori sikap memberikan kewenangan kepada suara wanita itu sendiri. Teori ini menyatakan bahwa pengalaman, pengetahuan, dan perilaku komunikasi perempuan dibentuk sebagian besar oleh kelompok-kelompok sosial di mana mereka berada. Dengan demikian, teori ini menunjuk pada masalah dalam tataran sosial dan menunjukkan cara-cara baru untuk mengatur kehidupan sosial sehingga akan lebih pantas dan adil (West, Turner, 2018).

Berdasarkan hasil wawancara mengenai penerimaan khalayak wanita atas karakter Ji Sun Woo, menghasilkan dua kesimpulan penerimaan;

Informan 1: seorang wanita muda berusia 25 tahun. Pendidikan terakhir S1 Akutansi, dan bekerja sebagai karyawan swasta. Penerimaan makna informan ini berada di posisi hegemoni dominan. Dari hasil wawancara, Informan ini merasa Ji Sun Woo adalah seorang ibu yang kuat, mandiri, serta akan menjaga anaknya dengan segenap hati dan jiwa. Penerimaan makna tersebut sesuai dengan penggambaran karakter yang disampaikan oleh aktris pemerannya, Kim Hee Ae.

Berdasarkan Teori Sikap, Informan 1 ini memiliki situated knowledge yang membuat ia melihat angle karakter Ji Sun Woo dari kacamata seorang anak. Kebetulan, informan 1 ini adalah anak seorang Ibu tunggal. Jadi informan 1 betul-betul melihat bagaimana perjuangan seorang Ibu tunggal untuk membesarkan anak-anaknya sendirian. Berdasarkan situated knowledge yang ia miliki terhadap Ibu Tunggal, membuat Informan 1 merasa memiliki keterkaitan tinggi sehingga makna yang diterima dari karakter Ji Sun Woo linear dengan apa yang ingin disampaikan oleh pembuat pesan.

Informan 2: seorang ibu muda berusia 29 tahun. Pendidikan terakhir S-2 Psikologi Sains. Statusnya adalah ibu rumah tangga untuk fokus merawat satu anak laki-lakinya. Penerimaan makna informan ini berada di posisi negoisasi. Informan ini menerima makna karakter Ji Sun Woo sebagai seorang wanita yang kuat, tapi sebagai ibu ia kurang bisa memahami perannya yang harus hadir untuk anaknya secara emosional, bukan hanya memberi pemenuhan kebutuhan-kebutuhan materiilnya saja. Kekurangan inilah yang membuat Ji Sun Woo harus menghadapi prahara besar dalam kehidupan rumah tangganya. Informan 2 menempatkan dirinya sebagai khalayak yang melihat dari angle seorang ibu. Konsep Standpoint jelas sekali terlihat dari Informan 2, karena ia banyak menilai dan memaknai karakter Ji Sun Woo dari pendekatan psikologi, berdasarkan dari latar belakang pendidikannya.

Informan 3: seorang wanita muda berusia 28 tahun, sudah menikah tapi belum memiliki anak. Pendidikan terakhir S-1 Komunikasi, berprofesi sebagai karyawan swasta. Penerimaan informan ini berada di posisi hegemoni dominan. Penerimaan makna karakter yang dia serap adalah Ji Sun Woo seorang wanita karir yang pintar, sukses, dan mandiri.

Menurut Informan 3, pembawaan Ji Sun Woo yang tenang membuat karakter ini layak menjadi 
panutan tentang bagaimana seorang istri harus bersikap di saat-saat krisis. Informan 3 melihat karakter Ji Sun Woo dari angle seorang wanita yang peran utamanya adalah sebagai seorang istri. Dari latar belakang tersebut, terlihat bahwa titik berat pemaknaan karakter Ji Sun Woo oleh Informan 3 adalah pada peran Ji Sun Woo sebagai istri dari Tae Oh. Informan 3 memiliki konsep kuat dari Sexual Division of Labor. Dia menilai karakter suami Ji Sun Woo sebagai memalukan, yaitu berselingkuh akibat tidak bisa menerima Ji Sun Woo sukses berkarir sebagai dokter. Si suami merasa Ji Sun Woo haruslah berada dibawah derajatnya.

\section{KESIMPULAN}

Kesimpulan penelitian ini adalah persepsi dan pemaknaan atas karakter Ji Sun Woo oleh para informan berada di posisi yang berbeda-beda tergantung dari pengalaman dan peran yang dijalankan berdasarkan kehidupan sehari-hari masing-masing para wanita tersebut. Makna-makna tersebut berbeda karena para wanita ini melihat dan menempatkan sikap serta sudut pandang mereka sebagai seorang anak, seorang wanita yang fokus pada peran ibu, dan seorang wanita yang berperan utama sebagai seorang istri.

Secara umum, Ji Sun Woo di mata informan digambarkan sebagai sosok karakter wanita kuat, tapi penilaian makna yang lebih terperinci dibalik makna "wanita kuat" tersebut, ditemukan pemaknaan yang berbeda-beda bagi masing-masing informan. Hasil pemaknaan tersebut adalah buah dari sikap atau Standpoint yang didapatkan dari pengalaman latar belakang kehidupan informan, tingkat pendidikan, dan juga peran dominan yang dijalankan para wanita informan tersebut, walaupun mereka semua adalah wanita.

\section{DAFTAR PUSTAKA}

Arivia, G. (2006). Feminisme: Sebuah Kata Hati. Jakarta: Penerbit Buku Kompas.

Berto, A.R. (2018). The Capitalization of Backpacking Tourism Culture in Indonesian Films , Jurnal Komunikasi Ikatan Sarjana Komunikasi Indonesia, 3(1), 1-11.

Elvinaro, A., Lukiati, K., Karlinah, S. (2007) Komunikasi Massa Suatu Pengantar. Bandung: Refika Offset.

Faizal, A.R. (2017). Flip and Switch - Minority and Cult Film in Indonesian Cinema, Jurnal Komunikasi Ikatan Sarjana Komunikasi Indonesia, 2(1), 40-47.

Griffin, J. (2009). Customer Loyalti: How to learn it, How to Keep it. Jakarta. Erlangga.

Mahardika, N. (2014). Pemaknaan Khalayak terhadap Sosok haji dalam Sinetron Tukang Bubur Naik Haji. Interaksi online, 2019 by http://ejournal3.undip

McQuaill, D. (2011). Mass Communication Theory. Jakarta: Salemba Humanika.

Morissan. (2003). Teori Komunikasi: Individu Hingga Massa. Jakarta: Kencana.

Morissan. (2007). Periklanan dan Komunikasi Pemasaran Terpadu. Tangerang: Ramdina Prakarsa.

Purnamasari, N.I. (2020). Audience Reception Related to Freedom of Life Partner in Aladdin Film. Jurnal Komunikasi Ikatan Sarjana Komunikasi Indonesia, 5(1), 31-41.

Putriana, I. (2012). Peran Gender Perempuan Militer dalam Majalah Korps Wanita Angkatan Darat Melati Pagar Bangsa. Jurnal Komunikasi Indonesia, 1(1).

Ratna, N.K. (2010). Metodologi Penelitian: Kajian Budaya dan Ilmu Sosial Humaniora pada Umumnya. Yogyakarta: Pustaka Pelajar.

Ritonga, R., Nugroho, E., Handoko, D. (2019). Struggle of Meaning and the Jokowi Myth in the 2018 Asian Games Opening Video, Jurnal Komunikasi: Malaysian Journal of Communication, 35(1), 137-155.

Siregar, R.A., Sulistyani, H.D. (2019). Resepsi Khalayak terhadap Karakter Difabel dalam Film Wonder. Interaksi Online by http://ejournal-.undip.ac.id.

Sobur, A. (2012). Analisis Teks Media: Suatu Pengantar Analisis Wacana, Analisis Semiotika, dan Analisis Framing. Bandung: Remaja Rosdakarya.

West, R., Lynn H.T. (2018). Pengantar Teori Komunikasi. Jakarta. Salemba Humanika. 